\title{
High HIV prevalence in an early cohort of hospital admissions with COVID-19 in Cape Town, South Africa
}

\author{
A Parker, ${ }^{1,2}$ MB ChB, FCP (SA), MMed (Int), Cert ID (SA) Phys; C F N Koegelenberg, ${ }^{3}$ MB ChB, MMed (Int), FCP (SA), FRCP (UK), \\ Cert Pulm (SA), PhD; M S Moolla, ${ }^{1}$ MB ChB; E H Louw, ${ }^{3}$ MB ChB, FCP (SA), MMed (Int); A Mowlana, ${ }^{1}$ MB ChB, FCP (SA), MMed (Int); \\ A Nortjé, ${ }^{3} \mathrm{MB}$ ChB, FCP (SA), MMed (Int); R Ahmed, ${ }^{1} \mathrm{MB}$ ChB; $\mathbf{N}$ Brittain, ${ }^{1} \mathrm{MB}$ ChB; U Lalla, ${ }^{3} \mathrm{MB}$ ChB, FCP (SA), MMed (Int), \\ Cert Crit Care (SA) Phys; B W Allwood, ${ }^{3}$ MB ChB, FCP (SA), Cert Pulm (SA), MPH, PhD; H Prozesky, ${ }^{2}$ MB ChB, MMed (Int); \\ N Schrueder, ${ }^{1}$ MB ChB, FCP (SA); J J Taljaard, ${ }^{2}$ MB ChB, MMed (Int), DTM\&H \\ ${ }^{1}$ Division of General Medicine, Department of Medicine, Faculty of Medicine and Health Sciences, Stellenbosch University and Tygerberg \\ Hospital, Cape Town, South Africa \\ ${ }^{2}$ Division of Infectious Diseases, Department of Medicine, Faculty of Medicine and Health Sciences, Stellenbosch University and Tygerberg \\ Hospital, Cape Town, South Africa \\ ${ }^{3}$ Division of Pulmonology, Department of Medicine, Faculty of Medicine and Health Sciences, Stellenbosch University and Tygerberg Hospital, \\ Cape Town, South Africa
}

Corresponding author: A Parker (aparker@sun.ac.za)

\begin{abstract}
Background. South Africa (SA) has a high prevalence of HIV and tuberculosis. Cape Town was the SA metropole most affected in the early stages of the COVID-19 pandemic. Early observational data from Africa may provide valuable insight into what can be expected as the pandemic expands across the continent.

Objectives. To describe the prevalence, clinical features, comorbidities and outcome of an early cohort of HIV-positive and HIV-negative patients admitted with COVID-19.

Methods. This was a descriptive observational study of an early cohort of adults with COVID-19 pneumonia admitted from 25 March to 11 May 2020.

Results. Of 116 patients (mean age 48 years, 61\% female) admitted, 24 were HIV-positive (21\%). The most common symptoms reported were cough $(n=88 ; 73 \%)$, shortness of breath $(n=78 ; 69 \%)$, fever $(n=67 ; 59 \%)$, myalgia $(n=29 ; 25 \%)$ and chest pain $(n=22 ; 20 \%)$. The most common comorbidities were hypertension $(n=46 ; 41 \%)$, diabetes mellitus $(n=43 ; 38 \%)$, obesity $(n=32 ; 28 \%)$ and HIV $(n=24 ; 21 \%)$. Mortality was associated with older age (mean (standard deviation) 55 (12) years v. 46 (14) years; $p<0.01$ ); the presence of hypertension or hypertension along with diabetes and/or obesity; lower partial pressure of arterial oxygen to fraction of inspired oxygen ratio; and higher urea level, white cell count, neutrophil count, and C-reactive protein, lactate dehydrogenase and ferritin levels, and high neutrophil to lymphocyte ratio. The overall survival rate for all hospital admissions was $86 / 116(73 \%)$. In this early cohort, survival was similar in patients with HIV $(n=18 ; 75 \%)$ compared with those without HIV $(n=67 ; 75 \%)(p=1)$. Of the 74 patients admitted to the wards, 63 ( $85 \%)$ survived, whereas 22 of $42(52 \%)$ admitted to the intensive care unit survived.

Conclusions. Patients with HIV infection represented a large proportion of all COVID-19 admissions. The presentation and outcome of patients with HIV did not differ significantly from those of patients without HIV.
\end{abstract}

S Afr Med J 2020;110(10):982-987. https://doi.org/10.7196/SAMJ.2020.v110i10.15067

The first cases of COVID-19 were detected in South Africa (SA) on 5 March 2020, and in Cape Town on 11 March. ${ }^{[1]}$ Subsequently case numbers have escalated exponentially. Western Cape Province was the initial epicentre with the highest prevalence of confirmed cases, with just over $60 \%$ of all cases in SA. The majority of these were within the Cape Town metropole. ${ }^{[2]}$ At the time of writing, Tygerberg Hospital, a 1380 -bed tertiary referral hospital for both the Tygerberg and Khayelitsha (low-income) subdistricts, has had the greatest number of COVID-19 patients in the Western Cape. ${ }^{[3]}$

The potential impact and mortality of COVID-19 in SA are unknown at this stage. Although SA has a relatively young population (median age 25 years), ${ }^{[4]}$ many South Africans of all ages have risk factors for severe COVID-19 disease identified in other populations. Adult South Africans have an unusually high background prevalence of hypertension $(41.6-54 \%),{ }^{[5]}$ diabetes $(12.8 \%)^{[6]}$ and obesity (68\% of females, $31 \%$ of males). ${ }^{[7]}$ Non-communicable diseases are estimated to cause $43 \%$ of adult deaths in SA, of which $18 \%$ are caused by cardiovascular disease. ${ }^{[8]}$

Of further concern is that SA has the world's highest number of people living with HIV (PLHIV), estimated at 7.7 million. ${ }^{[9]}$ It is unknown what impact HIV, both treated and untreated, will have on COVID-19 outcomes. Furthermore, SA has one of the highest incidence rates of tuberculosis (TB) globally, 520/100 000 population in 2018, ${ }^{[10]}$ and the interaction of COVID-19 with TB is not clear. The importance of gaining early insights into the COVID19 pandemic on the African continent, especially for PLHIV, cannot be overstated. At-risk populations need to be urgently identified and managed appropriately, in a manner that is contextually relevant to the available resources.

\section{Objectives}

To describe the clinical features, comorbidities and outcome of 
an early cohort of confirmed COVID-19 pneumonia patients admitted to a dedicated COVID-19 hospital, and specifically describe the prevalence, clinical profile and outcome of PLHIV.

\section{Methods}

Study design, setting and population This single-centre descriptive study included all consecutive patients aged $>18$ years with a SARS-CoV-2-positive polymerase chain reaction result and radiological evidence compatible with COVID-19 pneumonia admitted to Tygerberg Hospital, Cape Town, between 24 March and 11 May 2020.

\section{Data collection}

Patients admitted to Tygerberg Hospital with COVID-19 were identified from the hospital COVID Unit's application-based registry. The registry was verified against nursing and administrative records in each of the COVID wards to ensure accuracy and completeness. Data were extracted from hospital records and laboratory results, using a standardised form, and included demographic details, symptoms, comorbidities, blood results, imaging results, admission to the ward or the intensive care unit (ICU), length of admission, and outcome (death or discharge). HIV status was obtained in all patients. Where the HIV status was negative or unknown, an HIV enzyme-linked immunosorbent assay was done on admission. Glycated haemoglobin ( $\mathrm{HbAlC})$ was measured on admission at the discretion of the primary caregivers. Where not available during the admission, the $\mathrm{HbA1C}$ within 4 months prior to admission was recorded. Obesity was documented on the standardised admission tool at the discretion of the primary caregivers.

Chest radiographs were categorised according to type and distribution of infiltrates by the consensus of two specialists from the Division of Pulmonology at Tygerberg Hospital. Infiltrates were classified as consolidation, alveolar, reticular or micronodular. Distribution of infiltrates was categorised into laterality (peripheral, central or diffuse) and distribution (basal, apical or diffuse).

All patients were followed up until discharge from hospital or death. The data were complete as at 23 May 2020.

\section{Statistical analyses}

Descriptive numerical data with a normal distribution were described using means and standard deviations (SDs), whereas nonnormal data were described using medians and interquartile ranges (IQRs). Chi-square or Fisher's exact tests were used to identify statistical significance for all categorical outcomes. When comparing the means of continuous data, the $t$-test was used when the data had a normal distribution and the Mann-Whitney $U$-test when the data did not have a normal distribution.

Statistical significance was set at $p<0.05$, and a $95 \%$ confidence interval was used.

\section{Ethics approval}

The study was approved by the Health Research Ethics Committee of Stellenbosch University (ref. no. N20/04/002_COVID-19).

\section{Results}

\section{Baseline data}

We identified 116 patients with COVID-19 admitted during the study period, and all were included in the analysis. Demographic and laboratory data were available for all patients. Clinical data including symptoms and comorbidities were available for 113 patients and chest radiographs for 115 . Outcome data were available for all patients. The first patient was admitted on 25 March 2020 and the 116th patient on 11 May. Patient numbers increased gradually throughout the study period (Fig. 1).

The mean (SD) age of patients was 48 (14) years, and there were more females $(n=71$; $61 \%)$ than males $(n=45 ; 39 \%)$. Patients who died were older than those who survived (mean (SD) age 55 (12) years v. 46 (14) years, respectively; $p<0.01)$.

The prevalence of HIV $(n=24)$ in this cohort was $21 \%$, and these patients had

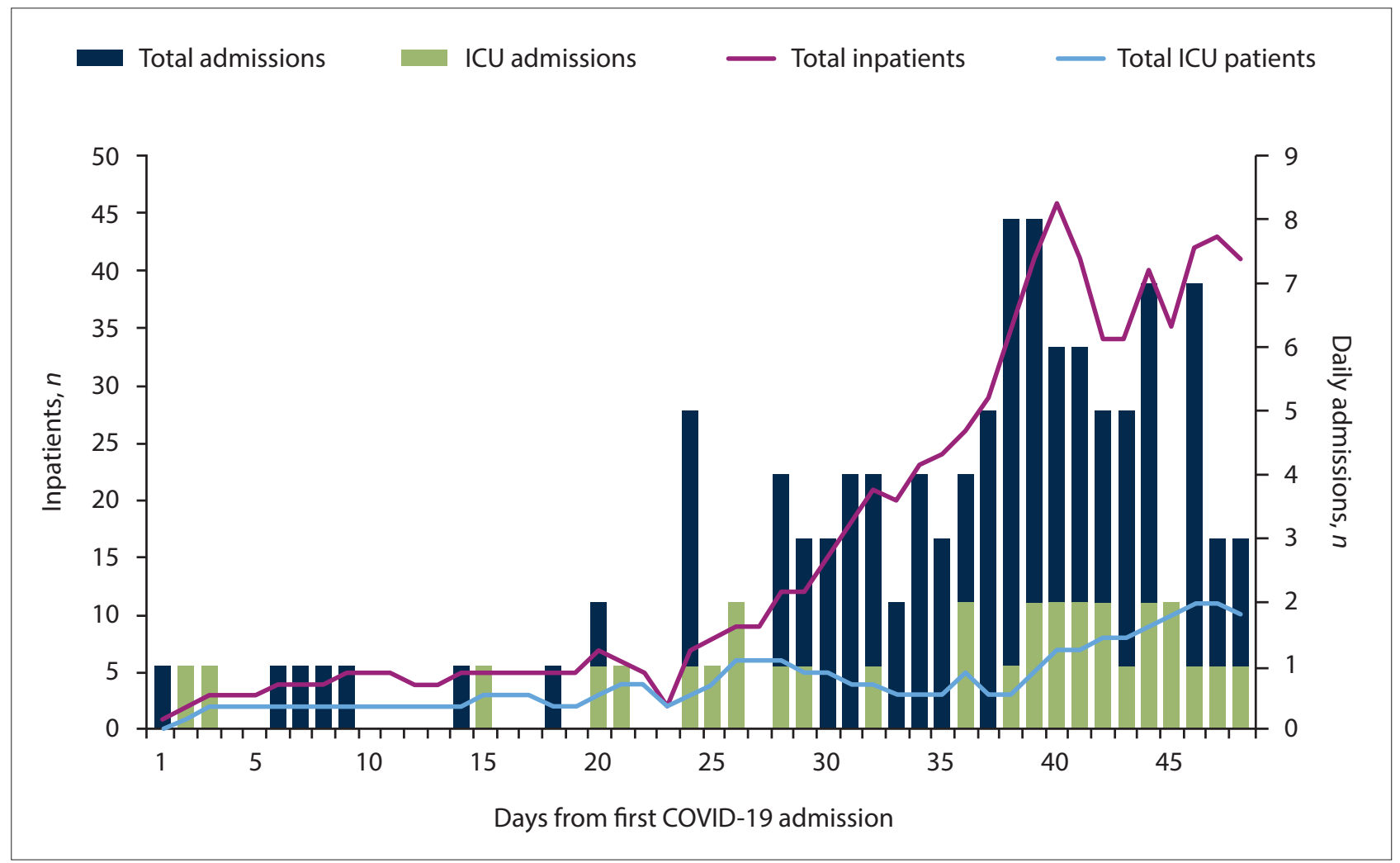

Fig. 1. Admissions over time. $(I C U=$ intensive care unit. $)$ 
a mean (SD) age of $46(9)$ years, with $18(75 \%)$ being female. The mean (SD) CD4+ count ( $n=16$ patients) was $325(206)$ cells $/ \mu \mathrm{L}$. Seventeen patients (71\%) were on antiretroviral therapy (ART) with suppressed HIV viral loads, 1 patient (4\%) was on ART but was failing the regimen, 4 patients (17\%) had a history of defaulting ART, and 2 patients $(8 \%)$ were ART naive. Patients with HIV had a trend towards shorter duration of symptoms prior to admission (5.4 v. 7.3 days; $p=0.26$ ).

A total of 4 patients (3.5\%) reported being on treatment for TB, while $9(8 \%)$ gave a history of previous TB. A history of smoking was present in 8 cases (7\%).

\section{Clinical features}

The most common reported symptom was cough $(n=88 ; 73 \%)$. This was followed by shortness of breath, fever, myalgia, chest pain and malaise (Table 1). Diarrhoea was reported by $13 \%$ of patients. Sore throat was infrequently reported. Symptoms in patients with HIV were similar, and none had sore throat as a presenting symptom.

The most common comorbidity reported was hypertension, followed by diabetes mellitus, obesity and HIV (Table 2). The presence of hypertension or hypertension along with diabetes and/or obesity was associated with high mortality.

Of the patients with HIV, 16 (76\%) had at least one other comorbidity (Table 3 ). The most common comorbidities in the

Table 1. Symptoms at baseline $(N=113)$

\begin{tabular}{ll}
\hline & $\boldsymbol{n}(\%)$ \\
\hline Cough & $88(77.9)$ \\
Shortness of breath & $78(69.0)$ \\
Fever & $67(59.3)$ \\
Myalgia & $29(25.7)$ \\
Chest pain & $22(19.5)$ \\
Malaise & $16(14.2)$ \\
Headache & $15(13.3)$ \\
Diarrhoea & $15(13.3)$ \\
Sore throat & $12(10.6)$ \\
Loss of smell & $11(9.7)$ \\
Loss of taste & $8(7.1)$ \\
Abdominal pain & $8(7.1)$ \\
Haemoptysis & $3(2.7)$
\end{tabular}

HIV-positive patients were diabetes, hypertension and obesity. HIVpositive patients were also more likely than those who were HIVnegative to have a prior history of TB $(n=6 ; 25 \%$ v. $n=3 ; 3 \% ; p<0.01)$.

Table 3. Clinical characteristics of HIV-positive and HIVnegative patients $(N=113)$

\begin{tabular}{|c|c|c|c|}
\hline & $\begin{array}{l}\text { HIV+ }(N=24 ; \\
21.2 \%)\end{array}$ & $\begin{array}{l}\text { HIV- }(N=89 ; \\
78.8 \%)\end{array}$ & $p$-value \\
\hline \multicolumn{4}{|l|}{ Demographics } \\
\hline Age (years), mean & 46.2 & 49.1 & 0.20 \\
\hline Male, $n(\%)$ & $6(25.0)$ & $38(42.7)$ & 0.18 \\
\hline Female, $n(\%)$ & $18(75.0)$ & $51(57.3)$ & 0.18 \\
\hline \multicolumn{4}{|l|}{ Symptoms, $n$ (\%) } \\
\hline Cough & $17(70.8)$ & $71(79.8)$ & 0.51 \\
\hline Haemoptysis & $2(8.3)$ & $1(1.1)$ & 0.11 \\
\hline Dyspnoea & $17(70.8)$ & $61(68.5)$ & 1.00 \\
\hline Fever & $15(62.5)$ & $52(58.4)$ & 0.89 \\
\hline Sore throat & 0 & $12(13.5)$ & 0.07 \\
\hline Loss of smell & $1(4.2)$ & $10(11.2)$ & 0.45 \\
\hline Loss of taste & 0 & $8(9.0)$ & 0.20 \\
\hline Diarrhoea & $4(16.7)$ & $11(12.4)$ & 0.73 \\
\hline Abdominal pain & $1(4.2)$ & $7(7.9)$ & 0.69 \\
\hline Chest pain & $5(20.8)$ & $17(19.1)$ & 1.00 \\
\hline Headache & $1(4.2)$ & $14(15.7)$ & 0.19 \\
\hline Malaise & $4(16.7)$ & $12(13.5)$ & 0.74 \\
\hline Myalgia & $5(20.8)$ & $24(27.0)$ & 0.73 \\
\hline \multicolumn{4}{|l|}{ Comorbidities, $n(\%)$} \\
\hline Hypertension & $8(33.3)$ & $38(42.7)$ & 0.55 \\
\hline Diabetes & $10(41.7)$ & $33(37.1)$ & 0.86 \\
\hline Dyslipidaemia & $1(4.2)$ & $9(10.1)$ & 0.46 \\
\hline Obesity & $5(20.8)$ & $27(30.3)$ & 0.51 \\
\hline Cardiac disease & $1(4.2)$ & $5(5.6)$ & 1.00 \\
\hline Malignancy & 0 & $1(1.1)$ & 1.00 \\
\hline Current TB & $2(8.3)$ & $2(2.2)$ & 0.21 \\
\hline Previous TB & $6(25.0)$ & $3(3.4)$ & $<0.01$ \\
\hline Other chronic lung disease & $2(8.3)$ & $4(4.5)$ & 0.61 \\
\hline Connective tissue disease & 0 & $1(1.1)$ & 1.00 \\
\hline Chronic kidney disease & $2(8.3)$ & $6(6.7)$ & 1.00 \\
\hline
\end{tabular}

Table 2. Comorbidities according to patient outcome $(N=113)$

\begin{tabular}{llllll}
\hline & Survivors $(\mathbf{N = 8 5}), \boldsymbol{n}(\%)$ & Deaths $(\mathbf{N}=\mathbf{2 8}), \boldsymbol{n}(\%)$ & $\mathbf{O R}$ & $\mathbf{9 5 \%} \mathbf{C I}$ & $\boldsymbol{p}$-value \\
\hline Hypertension & $30(35.3)$ & $16(57.1)$ & 2.4 & $1.0-5.8$ & 0.07 \\
Diabetes & $29(34.1)$ & $14(50.0)$ & 1.9 & $0.8-4.6$ & 0.20 \\
Hypertension + diabetes & $19(22.4)$ & $11(39.3)$ & 2.3 & $0.9-5.6$ & 0.13 \\
Hypercholesterolaemia & $8(9.4)$ & $2(7.1)$ & 0.7 & $0.2-3.7$ & 1 \\
Obesity & $23(27.1)$ & $9(32.1)$ & 1.3 & $0.5-3.2$ & 0.78 \\
Hypertension + diabetes + obesity & $7(8.2)$ & $6(21.4)$ & 3.0 & $0.9-10.0$ & 0.08 \\
Cardiac disease & $5(5.9)$ & $1(3.6)$ & 0.6 & $0.1-5.3$ & 1 \\
Malignancy & $1(1.2)$ & 0 & 0 & $\mathrm{n} / \mathrm{a}$ & 1 \\
HIV & $18(21.2)$ & $6(21.4)$ & 1.0 & $0.4-2.9$ & 0.81 \\
Current tuberculosis & $2(2.4)$ & $2(7.1)$ & 3.2 & $0.4-23.8$ & 0.26 \\
Previous tuberculosis & $5(5.9)$ & $4(14.3)$ & 2.7 & $0.7-10.7$ & 0.22 \\
Other chronic lung disease & $3(3.5)$ & $3(10.7)$ & 3.3 & $0.6-17.3$ & 0.16 \\
Connective tissue disease & $1(1.2)$ & 0 & 0 & $\mathrm{n} / \mathrm{a}$ & 1 \\
Chronic kidney disease & $5(5.9)$ & $3(10.7)$ & 1.9 & $0.4-8.6$ & 0.41 \\
CI = confidence interval; $\mathrm{n} / \mathrm{a}=$ not applicable. & & & & &
\end{tabular}


Table 4. Baseline arterial blood gas and laboratory results in survivors and non-survivors

\begin{tabular}{|c|c|c|c|c|c|c|c|}
\hline & \multicolumn{3}{|c|}{ Survivors } & \multicolumn{3}{|c|}{ Non-survivors } & \multirow[b]{2}{*}{$p$-value } \\
\hline & $n$ & Mean (SD) & $95 \% \mathrm{CI}$ & $n$ & Mean (SD) & $95 \% \mathrm{CI}$ & \\
\hline \multicolumn{8}{|l|}{ Arterial blood gas } \\
\hline $\mathrm{SaO}_{2}(\%)$ & 61 & $94(5.1)$ & $93-95$ & 19 & $82(14.1)$ & $75-89$ & 0.001 \\
\hline $\mathrm{PaO}_{2}(\mathrm{kPa})$ & 64 & $10.5(4.2)$ & $9.5-11.5$ & 25 & $8.1(4.4)$ & $6.3-9.9$ & 0.03 \\
\hline $\mathrm{FiO}_{2}(\%)$ & 67 & $33(0.19)$ & $28-38$ & 24 & $41(0.27)$ & $30-52$ & 0.17 \\
\hline $\mathrm{P} / \mathrm{F}$ ratio & 63 & $288(156)$ & $249-327$ & 24 & $188(112)$ & $141-235$ & 0.002 \\
\hline $\mathrm{PaCO}_{2}(\mathrm{kPa})$ & 63 & $4.7(1.3)$ & $4.4-5.0$ & 24 & $5.1(2.4)$ & $4.1-6.1$ & 0.44 \\
\hline $\mathrm{pH}$ & 63 & $7.44(0.06)$ & $7.42-7.46$ & 25 & $7.41(0.11)$ & $7.35-7.45$ & 0.10 \\
\hline \multicolumn{8}{|l|}{ Bloods } \\
\hline Sodium (mmol/L) & 84 & $136(4.3)$ & $135-137$ & 31 & $137(8.0)$ & $134-140$ & 0.77 \\
\hline Potassium (mmol/L) & 76 & $4.2(0.6)$ & $4.1-4.3$ & 31 & $4.3(0.9)$ & $4.0-4.6$ & 0.75 \\
\hline Urea $(\mathrm{mmol} / \mathrm{L})$ & 85 & $6.0(5.3)$ & $4.9-7.2$ & 31 & $12.0(12.1)$ & $7.6-16.4$ & 0.01 \\
\hline Creatinine $(\mu \mathrm{mol} / \mathrm{L})$ & 85 & $101(150)$ & $69-133$ & 31 & $194(321)$ & $77-311$ & 0.13 \\
\hline $\mathrm{WCC}\left(\times 10^{9} / \mathrm{L}\right)$ & 84 & $7.8(3.8)$ & $7.0-8.6$ & 31 & $11.6(6.7)$ & $9.2-14.0$ & 0.004 \\
\hline Neutrophils $\left(\times 10^{9} / \mathrm{L}\right)$ & 77 & $5.95(3.92)$ & $5-7$ & 28 & $9.22(6.40)$ & $6.74-11.7$ & 0.02 \\
\hline Lymphocytes $\left(\times 10^{9} / \mathrm{L}\right)$ & 77 & $1.55(1.87)$ & $1.13-1.97$ & 28 & $1.44(1.46)$ & $0.87-2.01$ & 0.76 \\
\hline $\mathrm{N} / \mathrm{L}$ ratio & 74 & $6(6)$ & $5-7$ & 28 & $10(9)$ & $7-13$ & 0.06 \\
\hline Haemoglobin (g/dL) & 84 & $12.13(2.6)$ & $11.43-12.57$ & 31 & $11.72(2.0)$ & $11.27-12.73$ & 0.37 \\
\hline MCV (fL) & 83 & $88(7.7)$ & $86-90$ & 31 & $90(6.9)$ & $88-93$ & 0.17 \\
\hline Platelets $\left(\times 10^{9} / \mathrm{L}\right)$ & 84 & $285(125)$ & $259-312$ & 31 & $303(149)$ & $248-358$ & 0.55 \\
\hline C-reactive protein $(\mathrm{mg} / \mathrm{L})$ & 72 & $128(105)$ & $103-153$ & 31 & $204(102)$ & $167-241$ & 0.001 \\
\hline LDH (U/L) & 46 & $400(165)$ & $351-449$ & 20 & 658 (199) & $565-751$ & $<0.0001$ \\
\hline ALT (U/L) & 52 & $36(30)$ & $28-44$ & 22 & $38(32)$ & $24-52$ & 0.77 \\
\hline Troponin T (ng/L) & 15 & $17(15)$ & $9-26$ & 11 & $65(84)$ & $8-122$ & 0.09 \\
\hline Creatine kinase $(\mathrm{U} / \mathrm{L})^{*}$ & 6 & $56(28-1218)$ & $\mathrm{n} / \mathrm{a}$ & 2 & $614(102-1126)$ & $\mathrm{n} / \mathrm{a}$ & 0.65 \\
\hline HbAlc (\%) & 42 & $9.1(3.5)$ & $8.0-10.2$ & 14 & $9.0(3.4)$ & $7.0-11.0$ & 0.89 \\
\hline Cholesterol (mmol/L) & 12 & $4.5(0.9)$ & $4.0-5.1$ & 7 & $3.9(2.4)$ & $1.7-6.2$ & 0.573 \\
\hline Ferritin $(\mu \mathrm{g} / \mathrm{L})$ & 23 & $976(775)$ & $642-1310$ & 14 & $2381(2448)$ & $1157-3605$ & 0.045 \\
\hline CD4+ (HIV+) $($ cells $/ \mu \mathrm{L})$ & 11 & $335(221)$ & $186-484$ & 5 & $304(193)$ & $64-544$ & 0.79 \\
\hline VL $(\mathrm{HIV}+)$ & 10 & LDL & & 3 & LDL & & \\
\hline $\mathrm{D}$-dimer $(\mathrm{mg} / \mathrm{L})^{*}$ & 19 & $0.5(0.3-1.1)$ & $\mathrm{n} / \mathrm{a}$ & 9 & $0.6(0.5-1.0)$ & $\mathrm{n} / \mathrm{a}$ & 0.41 \\
\hline PT (s) & 14 & $17.1(8.8)$ & $12.0-22.2$ & 11 & $20.1(23.7)$ & $4.2-36.0$ & 0.70 \\
\hline
\end{tabular}

\section{Investigations}

A low partial pressure of arterial oxygen to fraction of inspired oxygen $(\mathrm{P} / \mathrm{F})$ ratio and a high white cell count, neutrophil count, neutrophil to lymphocyte $(\mathrm{N} / \mathrm{L})$ ratio, and C-reactive protein (CRP), lactate dehydrogenase and ferritin levels were strongly associated with death. An elevated cardiac troponin level had a tendency to be associated with death, but this was not statistically significant (Table 4).

There was no significant difference in laboratory values between the HIV-positive and HIV-negative patients, except that patients with HIV were more likely to have anaemia at baseline.

Most patients had bilateral reticular infiltrates on chest radiography $(n=88 ; 77 \%)$ (Table 5$)$. Seven patients had radiological evidence of underlying structural lung disease. These included posttuberculous lung disease $(n=4)$, interstitial lung disease $(n=2)$ and aspergilloma $(n=1)$. None of the chest radiographs had evidence of chronic obstructive pulmonary disease. Micronodular infiltrates were strongly associated with mortality $(18 / 30 ; 60 \%$ v. $21 / 85 ; 25 \%$; $p=0.001$ ), while there was a trend towards increased mortality in patients with consolidation ( $p=0.06)$ and alveolar infiltrates $(p=0.08)$. Reticular infiltrates were not associated with mortality.

Most of the patients with HIV had bilateral reticular (19/24; 79\%) or micronodular infiltrates $(9 / 24 ; 38 \%)$. Patients with HIV were more likely than those without HIV to have underlying structural lung disease $(4 / 24 ; 17 \%$ v. $3 / 88 ; 3 \%$, respectively; $p=0.04)$. This included post-tuberculous lung disease in 3 patients, and an aspergilloma in 1 patient.

\section{Outcome}

Most patients (64\%) were admitted to the general ward ( $n=74)$, and $36 \%$ were admitted to the ICU $(n=42)$. When compared with HIVnegative patients, more HIV-positive patients tended to be admitted to the wards $(n=19 ; 79 \%$ v. $n=55 ; 62 \%)$ than to the ICU $(n=5 ; 21 \%$ v. $n=34 ; 38 \% ; p=0.18$ ). In the wards the median (IQR) length of stay (LoS) was 6 (3 - 10) days and in the ICU it was 6 ( 3 - 10) days. HIVpositive patients had a similar LoS (6 (IQR $3.5-10.5$, range 0 - 26) days) to HIV-negative patients (6 (IQR 3 - 10, range 0 - 28) days). In this early cohort, the median time from admission to ICU admission was $<1$ day. For the patients discharged from the ICU, the median (IQR) LoS was 15.5 (10 - 17) days.

The overall survival rate of all admissions was $86 / 116$ (73\%). In this early cohort, survival was similar in patients with HIV $(n=18 ; 75 \%)$ compared with those without HIV ( $n=67 ; 75 \%)$. Survival for patients admitted to the wards was $85 \%(63 / 74)$ and that for patients admitted to the ICU was $52 \%(22 / 42)$. 
Table 5. Baseline chest radiographic features $(N=115)$

\begin{tabular}{ll}
\hline & $\boldsymbol{n}(\%)$ \\
\hline Consolidation & $15(13.0)$ \\
Focal & $2(1.7)$ \\
Lobar & $4(3.5)$ \\
Multilobar & $6(5.2)$ \\
Bilateral & $3(2.6)$ \\
Alveolar infiltrates & $18(15.7)$ \\
Focal & 0 \\
Lobar & $3(2.6)$ \\
Bilateral & $15(13.0)$ \\
Reticular infiltrates & $88(76.5)$ \\
Focal & 0 \\
Lobar & $1(0.9)$ \\
Bilateral & $87(75.7)$ \\
Micronodular infiltrates & $39(33.9)$ \\
Focal & $1(0.9)$ \\
Lobar & 0 \\
Bilateral & $38(33.0)$ \\
Underlying disease & \\
PTBLD & $4(3.5)$ \\
COPD & 0 \\
ILD & $2(1.7)$ \\
Aspergilloma & $1(0.9)$ \\
Other & 0 \\
Laterality & \\
Peripheral & $12(10.4)$ \\
Central & $2(1.7)$ \\
Diffuse & $90(78.3)$ \\
Distribution & \\
Basal & $20(17.4)$ \\
Apical & $2(1.7)$ \\
Diffuse & $82(71.3)$ \\
PTBLD = post-tuberculous lung disease; COPD = chronic obstructive pulmonary disease; \\
ILD = interstitial lung disease. \\
& \\
& \\
\hline
\end{tabular}

\section{Discussion}

In this early report of the first 116 COVID-19 patients admitted to a referral hospital in Cape Town, SA, serving a population with a high prevalence of HIV, we found that PLHIV did not appear to have significantly worse outcomes compared with their HIV-negative counterparts. Our population, despite being younger than many other reported populations, exhibited a similarly high prevalence of cardiovascular comorbidities, including hypertension, diabetes mellitus and obesity.

Perhaps unsurprisingly, given the high background prevalence of HIV in SA, ${ }^{[11]}$ there was a higher prevalence of HIV in our study population compared with studies elsewhere. ${ }^{[12,13]}$ However, the HIV prevalence in this early cohort (21\%) appears to be almost double the estimated Western Cape provincial HIV prevalence of $12.6 \%$ in the age group 15 - 49 years. ${ }^{[11]}$ The reasons for this proportionally higher burden of HIV in our COVID-19 admission population compared with the background prevalence are not immediately clear, and should be interpreted with caution. It is unclear whether unknown referral bias played a role, or whether patients with HIV represent an increased risk of hospitalisation compared with an HIV-negative population.

However, reassuringly, the HIV-positive patients did not exhibit increased mortality, as was predicted prior to the COVID-19 pandemic reaching SA. The data from our study suggest that patients co-infected with HIV and SARS-CoV-2 have preserved CD4+ cell counts and suppressed HIV viral loads, and have concurrent cardiovascular comorbidities, including diabetes, hypertension and obesity. Interestingly, the CD4+ count and viral load did not differ between survivors and non-survivors with HIV, as may have been anticipated. However, the small sample size of HIV-positive patients limits drawing definitive conclusions on these matters, and larger cohort studies are urgently needed.

The proportion of patients in the study admitted to the ICU appears to be much higher than described in the $\mathrm{UK}^{[12]}$ and in New York, USA. ${ }^{[14]}$ The overall outcome in our study population, however, is similar to mortality rates described in the literature of $\sim 24.5$ 26\%.[12,14] Encouragingly, the presence of HIV did not appear to influence outcome significantly. Significant risk factors for mortality in our population echo those in other populations around the world, namely low arterial partial pressure of oxygen, low $\mathrm{P} / \mathrm{F}$ ratio, high CRP, high ferritin and high N/L ratio.

\section{Study limitations}

To our knowledge, this is the first cohort of $>100$ consecutive patients admitted with COVID-19 reported on the African continent, and from a population with a high burden of HIV and TB. However, our study has a number of limitations inherent in any study of this nature. Firstly, as this study was retrospective, data were not available for all variables, and were reliant on what was captured by the treating physician. For example, weight and body mass indices were not available for all patients, and information about obesity may have been underrepresented in this study. Secondly, as mentioned above, the sample size of HIV-positive patients was small, limiting definitive conclusions.

\section{Conclusions}

Our findings suggest that PLHIV with COVID-19 may have a high probability of admission to hospital, but had similar presentations, comorbidities and outcomes when compared with the HIV-negative study population. Large multicentre studies are needed to confirm these findings.

Declaration. None.

Acknowledgements. The authors wish to acknowledge all staff working in the COVID-19 Unit at Tygerberg Hospital.

Author contributions. AP conceptualised and drafted the manuscript. MSM, RA, NB, EHL and AP did the data collection. EHL and AN interpreted the chest radiographs. MSM did the data analysis. CFNK and JJT supervised the research. All authors contributed to the final manuscript.

Funding. None.

Conflicts of interest. None.

1. Parker A, Karamchand S, Schrueder N, et al. Leadership and early strategic response to the SARSCoV-2 pandemic at a COVID-19 designated hospital in South Africa. S Afr Med J 2020;110(6):463465. https://doi.org/10.7196/SAMJ.2020v110i6.14809

2. South African Government. Minister Zweli Mkhize confirms total of 70038 cases of coronaviraus South African Government. Minister Zweli Mkhize confirms total of 70038 cases of coronaviraus
COVID-19. 14 June 2020. https://www.gov.za/speeches/minister-zweli-mkhize-confirms-total-70COVID-19. 14 June 2020. https://www.gov.za/speeches/minister-Zweli-m

3. Western Cape Government. Covid-19 dashboard. https://coronavirus.westerncape.gov.za/covid-19dashboard (accessed 16 June 2020).

4. Statistics South Africa. Census 2011: Population dynamics in South Africa. Report No. 03 01-67. Pretoria: Stats SA, 2015. http://www.statssa.gov.za/publications/Report-03-01-67/ Report-03-01-672011.pdf (accessed 13 June 2020).

5. Gómez-Olivé FX, Ali SA, Made F, et al. Regional and sex differences in the prevalence and awarenes of hypertension: An H3Africa AWI-Gen study across 6 sites in sub-Saharan Africa. Glob Heart 2017;12(2):81-90. https://doi.org/10.1016/j.gheart.2017.01.007

6. International Diabetes Federation. IDF Africa members. https://www.idf.org/our-network/regionsmembers/africa/members/25-south-africa (accessed 18 June 2020).

7. National Department of Health, Statistics South Africa, South African Medical Research Council, ICE South Africa Demographic and Health Survey 2016: Key Indicators. Pretoria: Stats SA, 2017. https:// dhsprogram.com/pubs/pdf/FR337/FR337.pdf (accessed 14 June 2020). 
8. World Heart Federation. Cardiovascular diseases in South Africa. https://www.world-heartfederation.org/wp-content/uploads/2017/05/Cardiovascular_diseases_in_South_Africa.pdf (accessed 19 June 2020).

9. UNAIDS (Joint United Nations Programme on HIV/AIDS). Country: South Africa. https://www. unaids.org/en/regionscountries/countries/southafrica (accessed 20 June 2020).

unaids.org/en/regionscountries/countries/southafrica (accessed 20 June 2020).
0. World Health Organization. Global tuberculosis report 2019. 17 October 2019. https://www.who.int/ World Health Organization. Global tuberculosis report 2019).
tb/publications/global_report/en/(accessed 14 June 2020).

1. Simbayi LC, Zuma K, Zungu N, et al. South African National HIV Prevalence, Incidence, Behaviour and Communication Survey, 2017. Cape Town: HSRC Press, 2018

12. Docherty AB, Harrison EM, Green CA, et al. Features of 20133 UK patients in hospital with covid-19 using the ISARIC WHO Clinical Characterisation Protocol: Prospective observational cohort study. BMJ 2020;369:m1985. https://doi.org/10.1136/bmj.m1985
13. Karmen-Tuohy S, Carlucci PM, Zacharioudakis IM, et al. Outcomes among HIV-positive patients hospitalized with COVID-19. J Acquir Immune Defic Syndr 2020;85(1):6-10. https://doi.org/10.1097/ QAL.0000000000002423

14. Richardson S, Hirsch JS, Narasimhan M, et al.; and the Northwell COVID-19 Research Consortium. Presenting characteristics, comorbidities, and outcomes among 5700 patients hospitalized with COVID-19 in the New York City area. JAMA 2020;323(20):2052-2059. https://doi.org/10.1001/ jama. 2020.6775

Accepted 13 August 2020. 